\title{
PROSPECCION MICOLOGICA \\ EN RIZOSFERA Y RIZOPLANO EN UN VIVERO FORESTAL DE Eucalyptus globulus Labill EN LA V REGION (CHILE)
}

\author{
(Mycological prospection in rhizosphere and rhizoplane in a forest nursery of \\ Eucalyptus globulus Labill in the V Region - Chile)
}

\author{
E.Piontelli,L*., M.A. Grixolli,A*. \& S. Moraga, $C^{* *}$ \\ *Universidad de Valparaiso, Esc. de Medicina, Cátedra de Micologia, Casilla 92 V. Valparaiso \\ **Universidad Austral de Chile, Valdivia
}

Palabras clave: Vivero forestal, Eucalyptus globulus, hongos de la rizósfera y rizoplano.

Key words: Forest nursery, Eucalyptus globulus, rhizosphere and rhizoplane fungi.

\section{RESUMEN}

A pesar de que la la fumigación-esterilización de los suelos es de utilidad en la producción de los viveros forestales, la microbiota residente puede sufrir alteraciones dificiles de evaluar. Con la finalidad de detectar especificamente las variaciones de la micota $y$ corroborar el manejo sanitario, se efectio un muestreo en rizósfera y raices de plántulas de Euculyptus globulus Labill (Diciembre'93 a Julio'94), para evidenciar la presencia de patógenos, oportunistas y saprófitos. La metodologia, basada en la selección de muestras al azar. desde las platabandas, consistió en procesar la rizósfera. en suelos fumigados y esterilizados, mediante diluciones en cultivos sólidos (DCPA) y las raices, en agar agura, previa esterilización superficial y en medios especificos para Phytophthora y Pythium.

Se aislaron un total de $16+3$ colonias representadas por 40 géneros y 72 especies. En rizósfera, los principales taxa considerados como patógenos uoportunistas, fueron los géneros: Aspergillus (12,1\%) confrecuencias similares en las tres etapas y Fusarium (11,1\%) que decayó en la etapa final. En cambio los saprófitos de mayor presencia fueron Cladosporium $(8,7 \%)$, Penicillium $(8,4 \%)$ y Botryotrichum (6\%).

En raiz, los principales patógenos integraron los géneros: Pythium (sin porcentaje por metodologia diferente), Fusarium $(1+, 6 \%)$ y Trichoderma ( $+\%) . \quad F$. oxysporum $(82,5 \%$ del total del género), aumentó considerablemente en el segundo y tercer muestreo. mientras T. harzianum, fue siempre dominamte $18.5,9 \%$ adel rotal). Los saprofitos fueron representados mayoritariamente por Penicillium (16\%), Ulocladium (9,7\%) y Acremonium(2,2\%).

La baja mortalidad observada en las plámulas del vivero durante los muestreos, puede atribuirse en cierta

\section{SUMMARY}

Despite the benefits that fumigation-sterilization have in the production of forest murseries, the resident microbiota can undergo alterations that are difficult to evaluate. With the end objective of detecting the specific variations in the soil microorganisms and evaluating their sanitarymanagement, the rhizosphere and rhizoplane of Euculiptus globulus Labill seedlings were sampled (December 1993 - July 1994) to determine the presence of pathogens, opportunists and saprophytes. The methodology, based in random sampling from the nursery bed, consisted in evaluating the rhizosphere in fumigated and sterilized soils, using dilutions of solid cultures (DCPA), and in assessing the roots in previously sterilized water. agar and in specific mediums for Phytophthora and Pythium.

A total of 1643 colonies were detected, represented by 40 genera and 72 species. In the rhizosphere, the principal taxa found out as pathogens or opportunists were the genera: Aspergillus (12.1\%), with similar fiequencies in the three stages, and Fusarium (11.1\%) which declined in the final stage. The saprophytes of major importance in the thizosphere were Cladosporium (8.7\%), Penicillium (8.4\%) and Botryotrichum (6\%).

In the rhizozphere, the principal pathogens were the genera: Pythium (without percentage for different methodology), Fusarium (14.6\%) and Trichoderma (t\%). F. oxysporum (82.5\% of the total genus) increased markedly in the second and third samples, while T. harzianum w'as dominam through all of the samples $8.5 .9 \%$ of the (otal). The saprophytes present in the roots were represented mainly by Penicillium (16\%), Ulocladium (9.7\%) and Acremonium (2.2\%).

The low mortality ohserved in the seedlings from the nursery: can be atrituted at least partially to: 1) the 
medida a: 1) la acción de los fungicidas empleados, 2) la competencia y antagonismo ejercido por los hongos saprófitos presentes en los suelos muestreados (resistentes a las fumigaciones) y 3) a los taxa "competentes de la rizósfera" como T. harzianumy F. oxysporum, que pueden ejercer un rol importante. Todos estos factores podrian contribuir al control de algunos fitopatógenos detectados principalmente en las raices tales como: Pythium ultimum, Alternaria alternata, Phoma Leveillei.

Las variaciones de las poblaciones fingicas en los suelos de viveros fumigados, deben evaluarse mediante controles periódicos en el tiempo.

\section{INTRODUCCION}

La industria forestal ha tenido un gran desarrollo en el pais, desde la creación del Decreto Ley. 701( 1974), sustentado principalmente por las plantaciones de Pinus radiata D.Don. En los últimos años se ha acentuado también un gran interés por otros árboles exóticos, tal como las especies de Eucalyptus, de la cual existen aproximadamente 171.520 hás.(INFOR,1993). Esta gran superficie plantada, se debe tundamentalmente a sus múltiples usos, madera aserrada, muebles, paneles aglomerados, chapas de recubrimiento, pisos, etc. Además del reciente interés por la producción de pulpa de fibra corta y la exportación de madera pulpableen trozos y astillas (INFOR-CORFO, 1991).

Esta Mirtacea, de gran adaptabilidad, ha permilido su desarrollo en una amplia gama de ambientes ecológicos, desde los desérticos hasta los templados frios, esto unido a una excelente combinación de rápido crecimiento, peso específico y producción volumétrica.

Varias empresas forestales nacionales, incorporarón a sus planes de forestación al Eucalipto. Por lo antcrior; el nivel de plantaciones para los próximos años podría ascender a unas 22.000 hás./año, proyectandose una existencia total de 300.000 hás para el año 2.000 (INF.OR-CORFO, 1991).

Actualmente la región posee unas 31.670 hás. (INFOR, 1993), concentrando el $21 \%$ del total deplantaciones de esta especie en el pais, esto la convierte en la segunda en importancia después de la VIII región (Borquez., 1987).

El conocimiento de las plagas y enlermedades que atacan a las especies de Euculyptus que crecen en Chile es escaso (Prado \& Barros, 1991), entre las claramente identificadas está la caida o "damping-oft", provocada por un conjunto de hongos pertenecientes a los géneros Phytophthora, Pythium, Fusarium, Rhizoctonia, Sclerotinia y otros, que atacan las plántulas en vivero poco despucs de su emergencia y se caracterizan por una pudrición rápida tanto en semillas, raices y plántulas suculentas (Kunstmann, 1978). Cylindrocladium spp., se ha encontrado en pudrición de raices, en vivero de $E$. nitens en la VI región action of the fungicides used, 2) the competition and antagonism by the saprophytic fungus present in the sampled soils (resistant to the fumigations) and 3) the rhizosphere competents taxa such as T. harzianum and $F$. oxysporum, which can exert a important role. All of these factors could contribute to the control of some of the phylopathogens detected primarily in the roots such as: Pythium ultimum, Alternaria alternata and Phoma leveillei.

Changes in the fungus populations in fumigated nursery soils should be evaluated through periodic controls.

(Ipinza, 1992); C. scoparium Morgan, ha provocado también notables perdidas; su área de distribución comprende practicamente todos los paises del mundo (Ipinza, 1992; Jacobs, 1981). C. clavatum Hodges \& May, se ha identificadoen viveros de Eucalyptus en Brasil, y C. quinqueseptutum Boedgin \& Reitsma, en la India (Métro, 1976).

Entre los patógenos del suelo que se hospedan en la tiema del material de vivero y atacan a $E$. globulus y otras especies, se incluyen formas especiales de Fusarium oxysporum, $F$. solani y hongos de los géneros Mycosphaerella, Cytospora y Phytophthora.

Phytophthora cinnamomi, causa daño en raices y cuellos de varias especies de Euculyptus en Chile (VII y VIII región) y en el mundo, además de un amplio rango de hospedadores. Es capaz de sobrevivir por mucho tiempo) produciendo clamidosporas en suelos forestales (Mackay \& Weste, 1985; Ipinza, 1992). Mycosphaerella cryptica (Cooke)Hansf. y M. nubilosa (Cooke) Hansf., pueden ocasionar daños notorios, la primera preferentemente en Euculyptus delegatensis, $E$. nitens y $E$. regnans y la segunda a todas las subespecies de $E$. globulus y a $E$. nitens (Jacobs, 1981).

Armillaria mellea, es uno de los patógenos más peligrosos y extendidos, ataca el sistema radicular de las plantas leñosas y produce su muerte en cualquier etapa de su desarrollo; su área de distribución comprende todos los paises del mundo, incluído Chile (De la Lama, 1976).

Otra causa muy común de enfermedades del tallo en plantas de vivero de Euculyptus es Sclerotinia fuckeliuna (de Bary) Fuckel (Jacobs, 1981). Botrytis cinerea, ataca tallos, brotes y hojas, nomalmente se presenta en otoño y afecta plántulas de $18 \mathrm{~cm}$. de altura o más. Los modemos viveros de Eucalyptus no escapan a la acción de este hongo, que ocasiona mermas importantes, cuando no se establecen medidas sanitarias (Ipinza, 1992; Muñoz, 1986).

Algunos asconicetos, como los oidios (Oidium eucalypti y Podosphaera spp.) que producen manchas blancas, sobre hojas de plántulas de más de 15 a $20 \mathrm{~cm}$. de altura, son ectoparásitos obligados que afectan a plántulas en vivero (Muñoz, 1986) 
La capacidad de alterar el equilibrio ecológico mediante el aporte a los suelos de cantidades cada vez mayores de potentes compuestos quimicos tóxicos y específicos, empleados para el control de plagas de insectos, u otros organismos, son la causa de efectos secundarios sobre las plantas u organismos útiles (Burges \& Raw, 1971). Esta situación habitual en viveros, mediante fumigaciones periódicas de los suelos, lleva a su esterilización parcial, eliminando ya sea los hongos indeseables (patógenos) como benéficos (saprófitos) (Daniel et al., 1982). A pesar de ello, algunos patógenos cosmopolitas logran mantenerse y adaptarse a las nuevas condiciones de estrés, lo que hace necesario para un buen manejo del vivero, conocer su densidad, fluctuación y dominancia en cada temporada.

Nuestro objetivo principal pretende comparar y determinar cualitativa y cuantitativamente, la comunidad fúngica presente en rizósfera y raices (rizoplano), capaz de crecer en cultivos no selectivos, en plántulas aparentemente sanas de $\boldsymbol{E}$. globulus, bajo condiciones normales de trabajo, a lo largo de un periodo de viverización no superior a los 6 meses desde su siembra.

Comoobjetivos secundarios: 1) Detectar la presencia específica de patógenos comunes, tales como Pythium y Phytophthora en cultivos selectivos y solamente en el rizoplano de plantas con cierto grado de anormalidad. 2) Evaluar (sólo con fines comparativos), la microbiota presente en rizósfera y rizoplano, en un pequeño pool de plántulas cultivadas en condiciones de suelos no esterilizados-fumigados previamente.

\section{MATERIALES Y METODOS}

\section{1) Muestreo}

La zona de muestreo fue el vivero "Torquemada" ubicado en la $V$ región en la provincia deValparaiso, en el área de la ciudad de Con-Con, a 10 kilómetros de la ciudad de Viña del Mar.

El universo muestreal comprendió 190 platabandas de $E$. globulus Labill, sembradas en macetas dé plástico. Dada la homogeneidad del vivero, se consideró significativo muestrear un total de 16 platabandas, las cuales se eligieron al azar en cada muestreo. De cada platabanda se seleccionaron 4 plántulas (al azar). Las platabandas a muestrear, y dentro de ellas las plantas seleccionadas, se determinaron utilizando, tablas de permutaciones al azar (Cochran,1973).

Se trabajó con muestras compuestas, o sea, cuatro plantas tomadas desde una misma platabanda, correspondieron a una sola muestra (pool). Por lo tanto, se tuvo un lotal del 6 muestras para cada tipo de substrato (rizósfera y raices), por cada muestreo.

La colección de las muestras se efectúo en tres períodos, para observar tres etapas de las plántulas; el primer muestreo conespondió a Preemergencia(5 a 7 días de sembradas), el segundo a Emergencia normal ( 15 a 20 días de sembradas) y el tercero a Postemergencia ( 4 a 6 meses de sembradas). Se tuvo especial cuidado de incluir en cada muestra solo la tierra adherida a las raices.

Extraídas las plántulas se cortó la raíz a la altura del cuello, se guardaron cada grupo de cuatro raices en bolsas de polietileno estéril. Todas las muestras se procesaron en el mismo dia. Los muestreos se realizaron entre Diciembre de 1993 y Julio de 1994.

Las plantas seleccionadas, se sometieron a una apreciación visual de su estado vigoroso y sanitario, considerando el siguiente cuadro patrón (Burschel \& Martinez, 1968; Ibarra \& Valenzuela, 1980; Muñoz \& Perez, 1981).

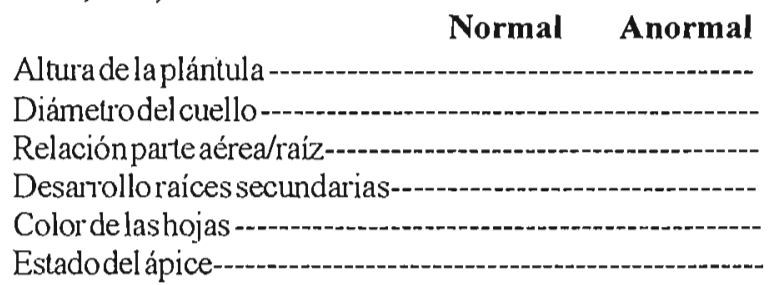

Aquellas plantas que presentaron una condición anormal en alguno de los aspectos observados fueron consideradas como probablemente infectadas y se trataron con una metodologia diferente (apropiada para detectar Phytophthora spp.o Pythium spp.) En esta situación la planta se reemplazó en el pool con otra que no presentara anormalidades.

\section{Procesamiento de las muestras \\ 2.1 Rizósfera}

Se agitaron manualmente las raices dentro de cada bolsa por dos minutos, para despegar la tierra adherida. Se pesó un gramo de este suelo y se disolvío en un tubo con $9 \mathrm{cc}$. de agua destilada estéril; esta se diluyó en series de tres tubos, hasta llegar a una concentración de 1:1.000 (tercer tubo), agitandose luego la mezcla manualmente por tres minutos. En seguida, por duplicado se depositó 0,1 cc. de esta solución ( $1: 1.000)$, dispersandola en la superficie de placas de Petri de $10 \mathrm{~cm}$. de diámetro, con el medio (DCPA) (Diclorán 0,0025gr./1t; Cloranfenicol 0,500gr./1t; Peptona $10 \mathrm{gr} . / \mathrm{t}$.; Agar $15 \mathrm{gr} . / \mathrm{tt}$.). Se sembraron 16 muestras por duplicado en cada muestreo.

\subsection{Raices}

Las raices se cortaron en trozos de $1 \mathrm{~cm}$. aproximadamente, se lavaron en agua potable, se desinfectaron en hipoclorito de sodio al $1 \%$ (con el objetivo de eliminar los hongos de la superficie), durante 5 minutos; terminado el tiempo de desinfección, se lavaron tres veces en agua destilada estéril. En seguida por duplicado se depositaron (4 a 5 trocitos de cada muestra) en la superficie de un medio sólido sin nutrientes en placas de petri de $10 \mathrm{~cm}$ (agar agua 
+ Caf $0,25 \mathrm{~g} / \mathrm{l}$ ), con la finalidad que las raices fueran practicamente el único sustrato para su crecimiento y el agar actuara como sostén y el aporte hídrico (cámara húmeda). Este procedimiento pretendió aislar los hongos capaces de colonizar la parte interna de las raices.

\subsection{Muestreo de control}

A pesar que ésta es una situación no empleada en los viveros forestales y no considerada en nuestro objetivo general, quisimos hacer un análisis comparativo.

En una dependencia anexa al vivero (que representó el universo del muestreo de control), se sembraron en macetas, semilla de $\boldsymbol{E}$. globulus (para obtener un total aproximadode 200 plántulas), empleandosuelosno tratados, para comparar los posibles cambios de la microbiota fúngica en ambas situaciones (suelos tratados y control). La metodología empleada fue la misma expresada en todos los puntos anteriores, pero debido al escaso número de plántulas se redujo el número de éstas a muestrear (2 pool de 4 plántulas por cada muestreo).

\subsection{Procesamiento especial de la raíz para detectar Phytophthora spp. o Pythium spp. en plantas con proble- mas sanitarios.}

Como el aislamiento de especies de Pythiaceae no es posible o poco probable con la metodología anterior, debido a la esterilización con hipoclorito de sodio, se emplearon técnicas selectivas solo en las plántulas con alguna anormalidad visual (según cuadro anterior), para observar la presencia de estos patógenos potenciales en raíz. Esta situación es un punto complementario a nuestro objetivo principal.

En las plántulas seleccionadas que presentaban sintomas de marchitez, se lavaron sus raices en agua potable, se desinfectaron en etanol $70 \%$, durante 15 a 30 segundos y se lavaron 2 veces en agua destilada esteril, luego se sembraron cuatro trozos de raiz de $1 \mathrm{~cm}$. aproximadamente, en un medio selectivo para Phytophthora y Pythium (Agar PAR, Kannwischer \& Mitchell, 1978).

Todas las placas se incubaron a temperatura ambiente de laboratorio $\left(13\right.$ a $18^{\circ} \mathrm{C}$, en los, meses frios y 17 a $23^{\circ} \mathrm{C}$, en los cálidos), hasta completar 30 días de incubación. Se revisaron a los 7,15 y 30 días.

\subsection{Identificación taxonómica}

La identificación taxonómica de los hongos a nivel de género y/o especie, se realizó con la ayuda de la lupa estereoscópica o microscopio (tinciones con lactofenol y azul de algodón) y el manual de identificación de Domsh etal. (1980).

La determinación de las cepas que esporularon directamente sobre las raices o en los medios de cultivos, se efectúo in situ. En la determinación de los géneros
Penicillium, Aspergillus y Fusarium, se emplearon subcultivos en medios específicos, acorde a las monografias de: Pitt, 1979; Klich \& Pitt, 1988; Nelson et al. 1983)

\subsection{Tratamiento químico de las semillas y el suelo en el} vivero

El suelo del vivero se esteriliza anualmente con Bromuro de metilo en una dosis de $0,25 \mathrm{lt} . / \mathrm{m} 3$, ocho días antes del llenado de los contenedores de plástico.

Un día antes de sembrar se aplicó al suelo MONSEREN (Bayer), en una dosis de 2lt.há. Postsiembra se aplicó BAYER 5072 en dosis de $2 \mathrm{~kg}$./há. a los 7,14 y 21 días de sembrado. Entre los meses de Marzo a Agosto se aplicaron los siguientes productos:RONILAND (BASF), fungicida de contacto, en dosis de 1,5kg./há; FOLICUR (Bayer), fungicida sistémico, en dosis del lt./há. y EUPAREN (Bayer), fungicida de contacto, en dosis de 1,5kg./há., estos productos se aplicaron en forma alternada, cada 10 a 14 días.

En forma localizada (solo donde se presentó el problema), se aplicaron: POMARSOL para agallas de cuello, $250 \mathrm{gr}$./há.; BOLATON 500, para gusanos cortadores, $60 \mathrm{cc}$./ 1t. de agua y TAMARON, para insectos (hormigas), $60 \mathrm{cc} . /$ $15 \mathrm{lt}$. de agua. Previo a la siembra se aplicarón los siguientes herbicidas: RAUNDAP(3,5lt./4.000m2) y UNIFILM(0,5lt./ $4.000 \mathrm{~m} 2$ ). Las semillas se esterilizaron con POMARSOLen dosis de $0,003 \mathrm{gr}$./semilla, el día anterior a la siembra.

\section{RESULTADOS}

En los 3 muestreos se aislaron en ambos substratos un total de 1643 colonias: en rizósfera, 304, 302, 368 y en rizoplano, $117,182,370$ (Tabla 1.), representando un total de 40 géneros y 72 especies. Los géneros mayoritarios en especies fueron Penicillium (1 I spp.); Aspergillus (9spp), Acremonium, Phoma y Scopulariopsis (4 spp. cada uno) (Tabla 1).

De la totalidad de los géneros aislados en ambos substratos, 13 se consideraron como patógenos potenciales Alternaria, Aspergillus, Botrytis, Cylindrocarpon, Drechslera, Fusarium, Microsphaeropsis, Myrothecium, Paecilomyces, Phoma, Pythium, Trichoderma y Verticillium, siendo Fusarium, Pythium y Alternaria los de mayor presencia (Tabla 1 ).

El porcentaje de patógenos en el rizoplano es un $11,5 \%$ mayor que en rizósfera, mientras.los saprófitos son más abundantes en rizósfera ( $12 \%$ ) (Gráfico 1). Al observar estas variables por etapa de muestreo, la cantidad de patógenos aumenta en cada muestreo en el rizoplano y disminuye en rizósfera, en cambio los saprófitos tienen un comportamiento inverso (Gráfico 2).

Observando el comportamiento global promedio en 
los 3 muestreos de las 10 principales especies o calegorias de hongos en ambos substralos, puede apreciarse que la mayoria de ellas disminuye cuantilativamente cn rizoplano, con excepción de F.oxysporum y T: harziamm y los micelios sin fructilicar, gue presentan aumentos de sus aislamientos (Grílico 4).

\section{Gráfico 1.- Aislamientos totales(\%) de hongos saprófitos y patógenos potenciales en rizósfera y rizoplano, en suelos tratados y control}

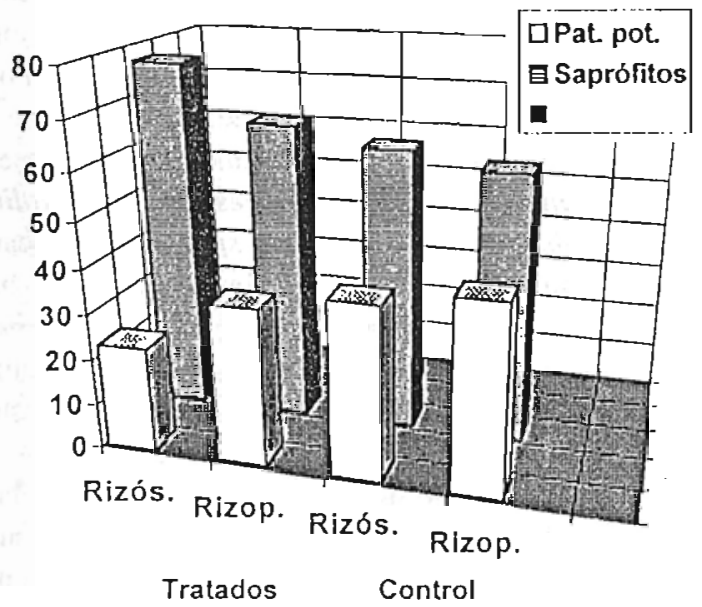

$1^{\circ}$ Muestreo (preemergencia) en suelos tratados.

Se aislaron un tolal de 421 colonials (rizisleca 182, rizoplano 68 y control 171), con 18 géncros y 36 especies, separados en 2 calegorias

a) Patógenos potenciales. lin rizósiera cl 28\% delos aislanientos fueron considerados cn esta calcgoria , siemelo F. oxy.porum (6\%) y $F$. moniliforme $(5,5 \%)$ los de may (or presencia, mientras en el rizoplano, hubo menor presencia (20,3\%), destacándose la alundancia de T. harziunum $(7,4 \%)$. Los géncros presentes en ambos substratos (incluyendo control) fueron Aspergillus y Fusarium (Tabla 1).

b) Saprófitos. Lin la rizósfera los principales géneros fucron Cladosporium y Penicillum, nicntrasen el riz.op) Jano solo Penicillium tuvo porcentajes más altos $(7,4 \%$ ). l.os géncros de saprólitos prescnles en los tres substratos (rizóslera, rizoplanoy control) liveron spp. de A cremonium, Cladosporium, Penicilliwn y Ulocladium (Tabla 1).

$2^{\circ}$ Muestreo(emergencia) en suclos tratados.

Seaislaron 484 colonias ( 189 rizóslera, 14 () rizon)lano y 155 control), 25 géneros y 34 cspecies.

a) Patógenos potenciales: En rizósfera se uburucl 25,4\% de los aislaniento, siendo F. oxysporum el demuyor presencia con $10,6 \%$ y $A$. versicolor con $(6,9 \%$, micullas cu el rizoplano la pesencia liue superior $(32.9 \%)$. desincandose la abundancia de Alernaria spp. (13.9\%). Los lavia presentes on ambos substralus y control liecon: Fasarium y Aspergillus. b) Saprofitos: Los taia de mayor presencia en rizósfera lieron Cladosporium cladosporioides (12,7\%) y' Ulocladium chartarum (9,5\%) y $\mathrm{cn}$ rizoplano $U$. atrum (10,7\%) y Penicillium janthinellum $(8,6 \%$ ) (Iab|a 1). Los laxas presentes en ambos substratos y control fueron: Cladosporium, Penicillum y Botryotrichum.

Grálico 2.- Aislamientos totales(\%) de hongos saprófitos y patógenos potenciales en rizósferay rizoplano, en suclos tratados poretapas de muest reo

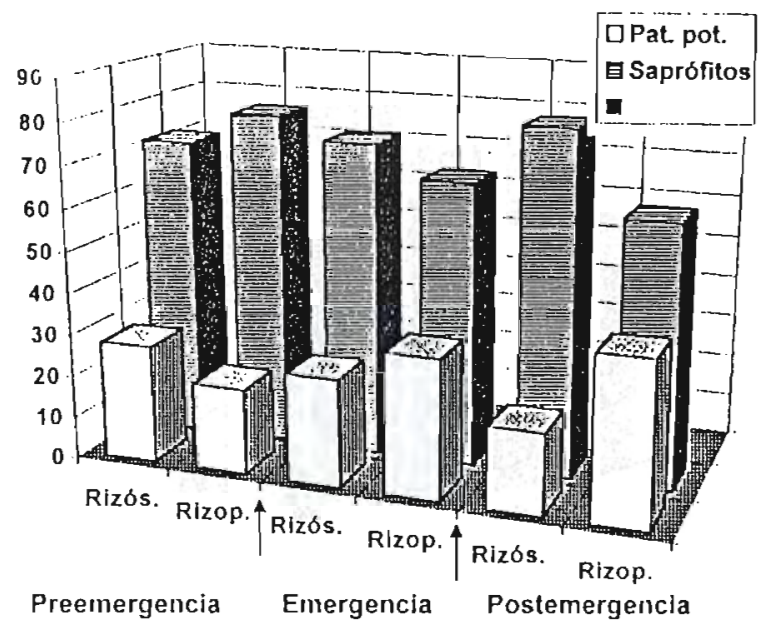

$3^{\text {n }}$ Muest reo (postemergencia) en suclos tratados.

Se aiski un kolal de 748 colonias (264 rizosfera, 328 rizoplano y 156 comtrol), 30 géncros y 37 especies

a) Patógenos potenciales: Łil riziselera se obluvo un 18,9\%, sicmedo los inlegrantes del género Fusarium los magoritarios (14,3\%). Fin el rizoplano el percentaje fice el más allo de los 3 muestrens, con un $38,1 \%$, siculo $F$. oxysporum $(24,3 \%)$ y Alternaria spp. (4,5\%)los que se cncontraron en mayor numero; el taxon presente en ambos substiatos, incluyendo el control fue Fusarium.

b) Saprófitos:len rizósfera deslacan: Botryotrichum piluliferum (11,4\%) y Penicillum janczewskii ( $8 \%$ ), mientras en rizoplano, $P$. janthinellum $(19,2 \%)$ y $P$. purpurogenum (4,6\%), fueron los más abundantes (Tabla 1).

Delse destacarse que en el rizoplano, con cl cmpleo de medios de cullivo selectivos para Phytophthora y Pythium, se obtuvo un $100 \%$ de presencia de Pythium sltimmm col las tres lases del muestreo.

Muestreo en suelos control

a) Patógchos. Se produce una importante dilerencia cn el porcentaje de hongos patogenos potenciales al comparat los cucontratos en el suclo tratado y control, en ambes substralus. Ia participación de éstos es sicmpre mityor en los sucks control en las tres elapas de muestreo $y$ in ambos substralus. lin rizostera, el porcentaje de 
participación se mantiene bastante constante en las tres etapas $(42,3 \% ; 40,6 \%$ y $40,2 \%$ respectivamente) siendo levemente mayor en preemergencia (2\%). En rizósfera los valores fueron más fluctuantes presentándose el más alto en el tercer muestreo $(39,4 \%)$ y el más bajo en el primer muestreo $(33,6 \%)$ (Gráfico 1 y 3 ).

Gráfico 3. - Aislamientos totales (\%) de hongos saprófitos y patógenos potenciales.en rizósfera y rizoplano en suelos no tratados(control) por etapa de muest reo

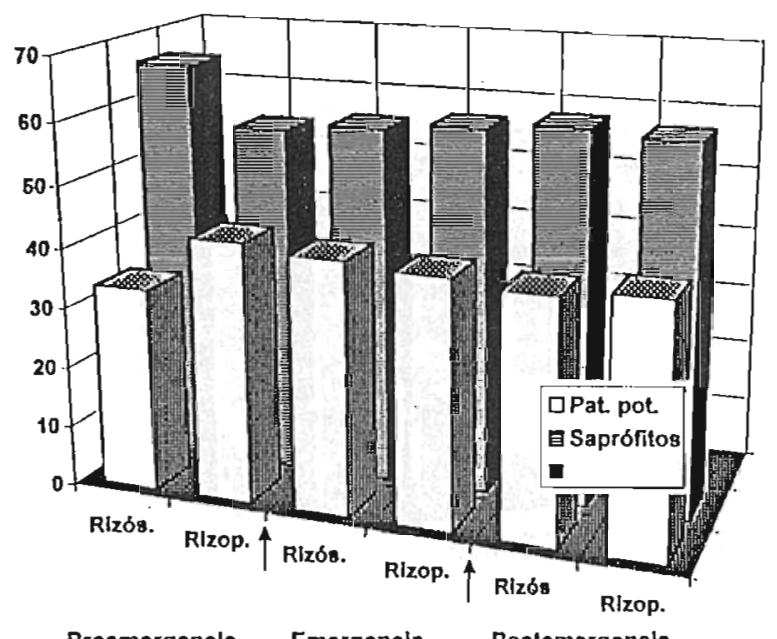

Preemergencla Emergencla Postemergencla

En raíz los géneros de mayor presencia fueron $A \boldsymbol{s}$ pergillus, Fusarium y Pythium, el número total de géneros de patógenos potenciales presentes en rizoplano es mayor que en rizósfera ( 5 y 3 géneros respeclivamentc), los 5 géneros identificados se encontraron presentes en las tres etapas pero con valores de participación muy flucluantes, Aspergillus spp. disminuyó en cada etapa de muestreo $(18,8 \%, 14,3 \%$ y $11,5 \%$ respectivamente) al igual que Trichoderma spp.(6,3\%, 2,4\% y 1,9\% respectivamente), cn cambio Fusarium spp. y Phoma spp. aumentarón en cada etapa de muestreo( $13 \% ; 16,7 \% ; 21,1 \%$ y $2,1 \% ; 2,4 \% ; 3,8 \%$ respectivamente). Alternaria spp. presentó una participación variable, aumentando en el segundo muestreo y disminuyendo nuevamente en el lercero.

En rizósfera los únicos géneros identificados fueron Aspergillus y Fusarium, (con excepción de una pequeña participación de Paecilomyces en el segundo muestreo), ambos taxa aumentaron su participación en cada elapa $(16,4 \% ; 17,7 \% ; 19,2 \%$ y $17,2 \% ; 19,4 \% ; 20,2 \%$ respectivamente) ( Tabla. 1).

b) Saprófitos. El numero de saprófitos aislados, en suelo tratado, es notablemente superior a los identificados en suelo no tratado (control), en ambos substratos y en las tres etapas de muestreo. Los géncı 3 s identificados que tuvieron mayor porcentaje de participación (Botryotrichum, Cladosporium, Penicillium, Scopulariopsis, Ulocladium), fueron también aislados en suelo tratado. Botry'otrichum fue el género con mayor participación en este tralamicnto, en ambos substratos y en las tres etapas estudiadas.

En rizoplano, el porcentaje de participación de saprólitos es bastante similar en los tres estados de la plántula (preemergencia 57\%, emergencia normal 59,5\% y postemergencia $59,6 \%$ ). En la etapa de preemergencia es donde se presenta la mayor diferencia en el porcentaje de participación de saprófitos, entre suelo tratado y no tratado $(79,6 \%$ y $57 \%$, respectivamente). Ulocladium es el género con mayor porcentaje de participación ( $26 \%$ del total de saprófitos aislados en este sustrato y en las tres etapas de muestreo), Botryotrichum y Penicillium lo siguen en importancia, con $17,8 \%$ de participación cada uno. Scopulariopsis y Cladosporium, se encontraron también en los tres muestreos, pero con menor porcentaje de parlicipación (10,7\% y $7,1 \%$ respectivamente). Otros géneros como Acremonium spp., Doratomyces spp., Gliocladium spp., Humicola spp. y Melanospora spp., se identificaron solo en algunas etapas de las plántulas y con baja participación (Tabla. 1).

. In rizósfera, el porcentaje de participación de hongos saprófilos, es un poco más variable que en raiz ( $1^{\circ} \mathrm{Muestreo}$ $66,3 \% ; 2^{\circ}$ Muestreo 58,5\% y $3^{\circ}$ Muestreo 60,5\%). En postemergencia es donde se presenta la mayor diferencia de participación de saprófitos en ambos tratamientos (suelo tralado $81,2 \%$ y control $60,5 \%$ ), en cambio en preemergencia estos valores son muy similares (tratado $67,9 \%$ y control $66,7 \%$ ), esta semejanza no se repite en raíz, donde por el contrario la diferencia supera el 10\%, siendo el porcentaje de participación mayor que en suelo tratado. El género con mayor participación es Botryotrichum spp. con 31,4\% del total de saprófitos aislados en este sustrato, en las tres elapas de muestreo, seguido por Scopulariopsis spp.(21,9\%), Penicillium spp.(14,3\%), Cladosporium.spp. ( 1 3,8\%) y Ulocladium spp.(3,3\%). Humicola spp. también se encontró presente en los tres estados de las plántulas, pero con muy bajo porcentaje de participación (1,4\%). Otros integrantes de los géneros tales como: Acremonium spp., Basipetospora spp., Doratomyces spp., Helicosporium spp. y Stachybotrys spp., se encontraron presentes solo en algunos muestreos y con baja participación, con excepción de Doratomyces spp, que se encontró solo en preemergencia, pero con alta participación (11,5\% de los saprófitos aislados en esa oportunidad y $6,6 \%$ del total aislados en las tres elapas de muestreo) (Tabla. 1).

\section{DISCUSION}

Las raices constituyen un habitat inestable para los microorganismos, debido a que las interfases entre éstas, el suelo y la microbiota, sufien continuos cambios en el tiempo. Los estudios sobre rizósfera y rizoplano han demostrado que estos habilat con alta densidad poblacional microbiana, son capaces de cjercer un significativo control sobre algunos patógcnos, ya sea por efectos antagónicos, parasitismo o competencia por la materia orgánica presente 
TABLA 1.- Frecuencia (\%) de microhongos totales en rizósfera y rizoplano por etapa de muestreo, en suelos tratados y control

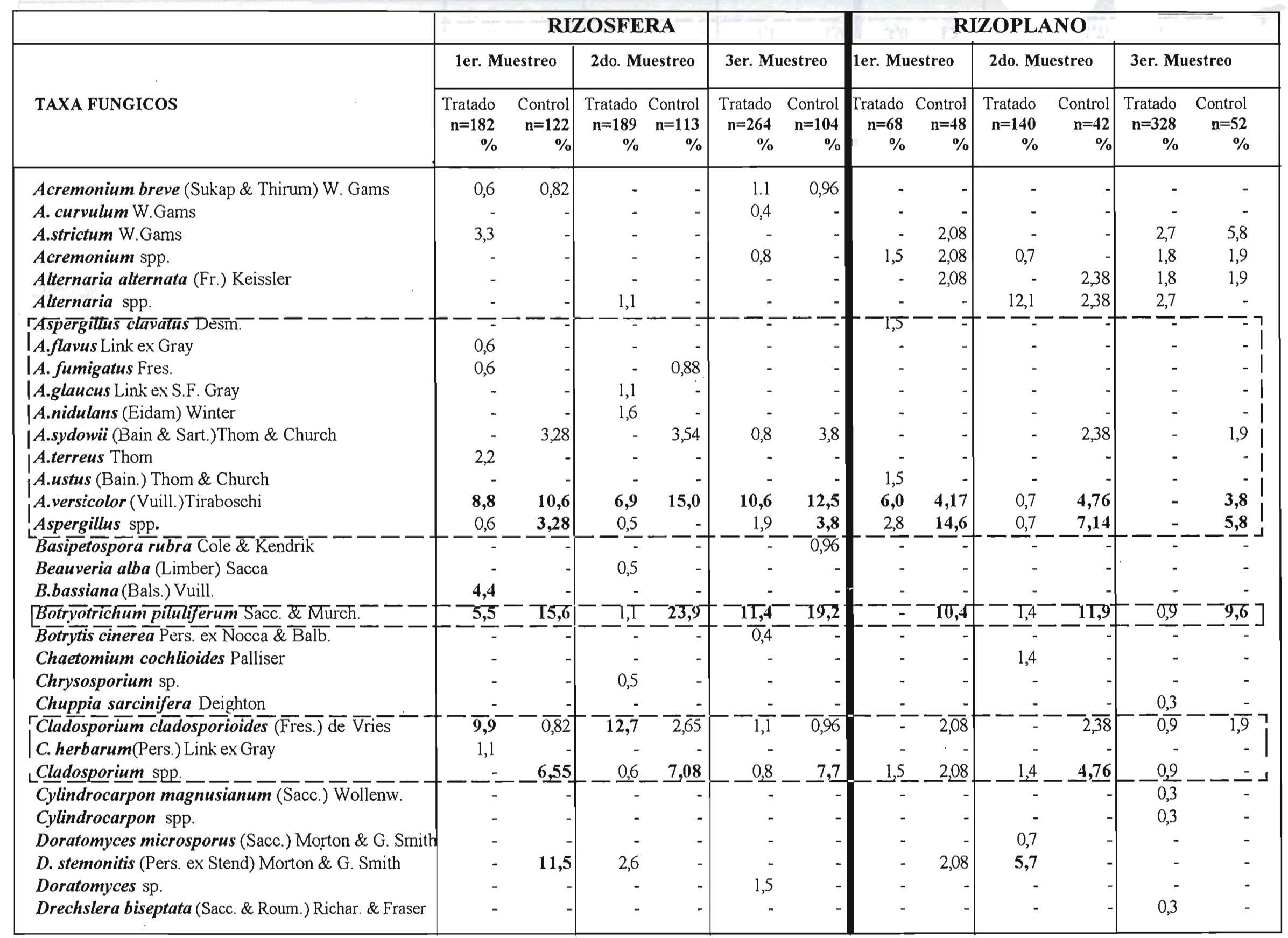


TABLA 1.(Continuación)

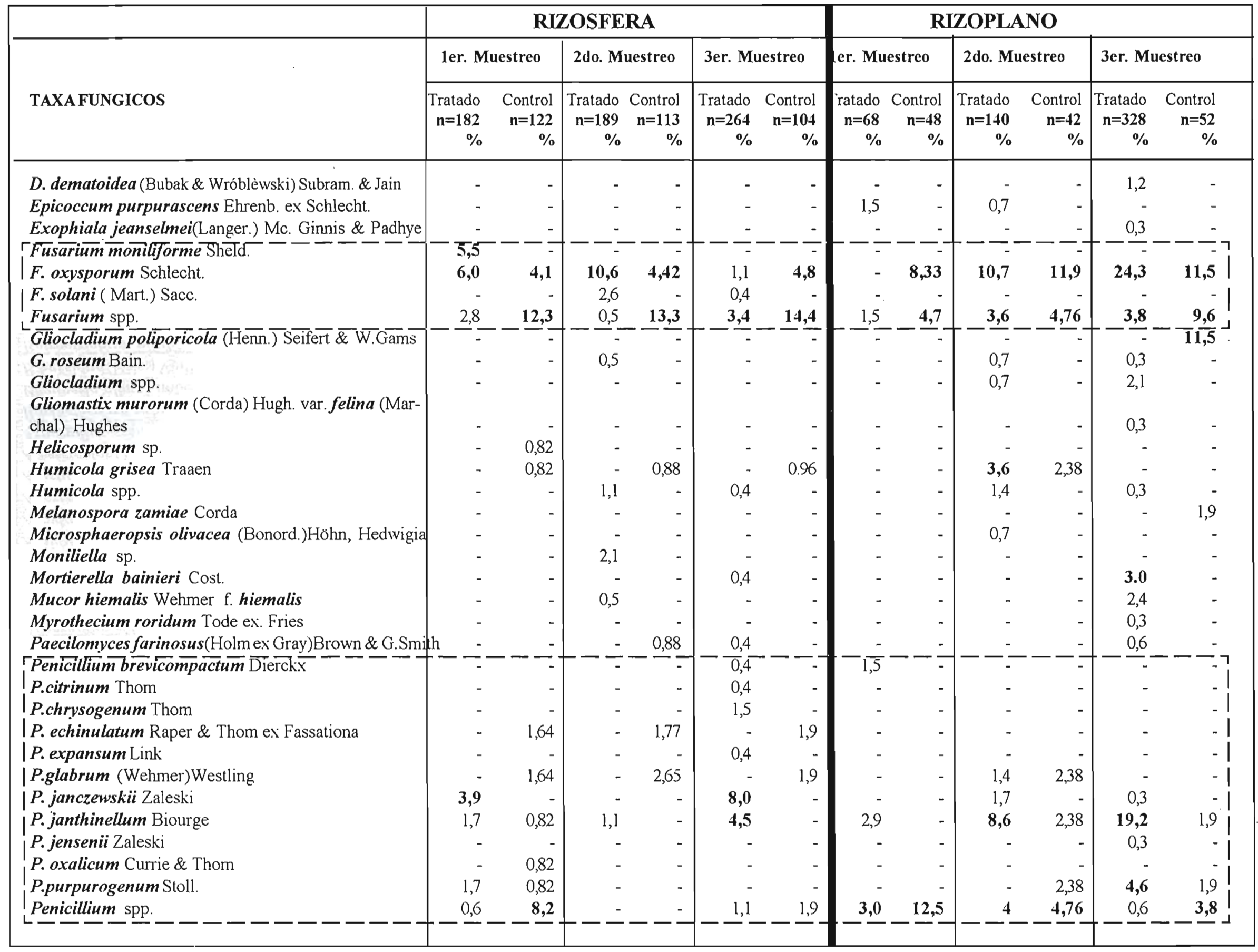


TABLA 1.-(Continuación)

\begin{tabular}{|c|c|c|c|c|c|c|c|c|c|c|c|c|}
\hline \multirow[b]{3}{*}{ TAXAFUNGICOS } & \multicolumn{6}{|c|}{ RIZOSFERA } & \multicolumn{6}{|c|}{ RIZOPLANO } \\
\hline & \multicolumn{2}{|c|}{ 1er. Muestreo } & \multicolumn{2}{|c|}{ 2do. Muestreo } & \multicolumn{2}{|c|}{ 3er. Muestreo } & \multicolumn{2}{|c|}{ ler. Muestreo } & \multicolumn{2}{|c|}{ 2do. Muestreo } & \multicolumn{2}{|c|}{ 3er. Muestreo } \\
\hline & $\begin{array}{r}\text { Iratado } \\
\mathrm{n}=182 \\
\%\end{array}$ & $\begin{array}{r}\text { Comliol } \\
n=122 \\
\%\end{array}$ & $\begin{array}{r}\text { Tratado } \\
\mathrm{n}=189 \\
\%\end{array}$ & $\begin{array}{r}\text { Control } \\
\mathrm{n}=113 \\
\%\end{array}$ & $\begin{array}{r}\text { Tratado } \\
\mathrm{n}=264 \\
\%\end{array}$ & $\begin{array}{r}\text { Control } \\
\mathrm{n}=104 \\
\%\end{array}$ & $\begin{array}{r}\text { Tratado } \\
\mathrm{n}=68 \\
\%\end{array}$ & $\begin{array}{r}\text { Contro] } \\
\mathbf{n}=48 \\
\%\end{array}$ & $\begin{array}{r}\text { Tratado } \\
\mathbf{n = 1 4 0} \\
\%\end{array}$ & $\begin{array}{r}\text { Control } \\
\mathrm{n}=42 \\
\%\end{array}$ & $\begin{array}{r}\text { Tratado } \\
\mathrm{n}=328 \\
\%\end{array}$ & $\begin{array}{r}\text { Control } \\
\mathrm{n}=52 \\
\%\end{array}$ \\
\hline Phoma glomerata (Corda) Wollenw \& I lochaplel & 0.6 & - & - & - & - & & - & & - & -1 & - & - \\
\hline P. herbarum Westend. & 0,6 & - & - & - &. & - & - & 2.08 & - & 2,38 & 0,3 & 1,9 \\
\hline P. Leveillei Boerema \& Bollen & - & - & - & - & - & - & - & & 0,7 & & 1,2 & 1,9 \\
\hline P. medicaginis Malbr. \& $\mathrm{R}$ oum. & - & - & 0,5 & - & - & - & - & - & - & - & - & - \\
\hline Pythium ultimum Trow: var ultimum & & & & & & & + & & + & & + & \\
\hline Rhinocladiella atrovirens Nannl'. & - & - & 1,1 & - & - & & - & & - & & 0,3 & - \\
\hline Scopulariopsis brevicaulis (Sacc $\overline{\text { Scain. }}$ & - & $\overline{0}, 8$ & $(0, \overline{5}$ & $\overline{0,88}$ & - & $0, \overline{6}$, & - & & - & & - & - \\
\hline S. brumptii Salvanct-1)uval & - & 4,92 & 1,6 & 5,31 & - & 5,8 & 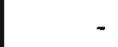 & 208 & $\ldots$ & 2,38 & - & 1,9 \\
\hline | S.candida (Giueglicn) Vuill. & 0,6 & 1.64 & 4,8 & 1,77 & 0,8 & 4,8 & - & - & - & & 0,3 & - \\
\hline S.flava (Sopp) Mortun \& Simith & - & & - & 0,88 & - & & - & - & - & - & - & - \\
\hline Scopulariopsis $:\left.\right|^{p}$ - & - & 4,1 & - & $-4,42$ & $=$ & 4,8 & & +.17 & - & 4,76 & - & 3,8 \\
\hline Sphaerosporium lignatile Sichucin. & $\bar{I}, \mathrm{I}$ & & - & - & - & & - & & - & - & - & - \\
\hline Stachybotrys atra Corda & - & 0,82 & - & - & - & & - & & 0,7 & & - & - \\
\hline Trichurus spiralis I lasiclbring & - & - & - & - & - & & - & - & 2,9 & ـ & - & - \\
\hline Torula herbarum li quaternella sice. & - & & - & - & - & & - & & - & & 0.3 & - \\
\hline 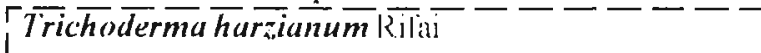 & - & - & - & - & - & & $\overline{7}, \overline{4}$ & $4, \overline{17}$ & $\overline{2,1}$ & & $\overline{0,9}$ & - \\
\hline Trichoderma splp. & - & & - & - & - & & - & 2.08 & 1,4 & 2,38 & 0,3 & 1,9 \\
\hline$r \bar{l}-\overline{-}-\overline{-}-------$ & -1 & & & & & & & & & & & \\
\hline 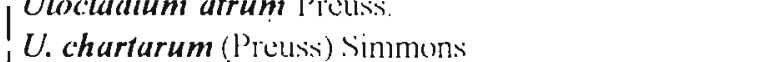 & 1,1 & $\begin{array}{r}2,40 \\
-\end{array}$ & 9,5 & $\begin{array}{l}0,88 \\
0,88\end{array}$ & $3,0^{-}$ & 1.9 & $\begin{array}{l}1,5 \\
-\end{array}$ & $\begin{array}{r}14,6 \\
2,08\end{array}$ & $\begin{array}{r}10,7 \\
0,7\end{array}$ & $\begin{array}{r}11,9 \\
2,38\end{array}$ & $\begin{array}{r}7,9 \\
-\end{array}$ & $\begin{array}{r}7,7 \\
1,9\end{array}$ \\
\hline U. oudemansii Simmons & - & - & - & - & - & & . & & 0,7 & & - & - \\
\hline Ulocladium spp. & - & & _ & & - & & 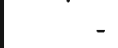 & - & 5,0 & 2,38 & 2,7 & 3,8 \\
\hline Verticilium psalliotae Treschow & & & & & & & & & - & & 0,6 & $=$ \\
\hline Levaduras (13lancas y rosiadas) & 110 & - & 12,2 & - & 9,5 & - & 1,5 & - & - & - & - & - \\
\hline Micelio sin fructificar (total, Hialino y Dematiaceo) & 25,8 & 0,82 & 21,2 & 2,65 & 33,7 & 5,8 & 64,7 & 5,6 & 12,9 & 2,38 & 7,6 & - \\
\hline ( Micelio hialino) & 24,7 & 0,82 & 16,3 & 1,77 & 19.3 & 2,9 & 53,1 & 5,6 & 2,6 & - & 4,9 & - \\
\hline (Micelio dematiaces) & 1,1 & -- & 5,2 & 0,88 & 14,4 & 2.9 & 11,6 & - & 10,3 & 2,38 & 2,7 & - \\
\hline
\end{tabular}




\section{Gráfico 4. - Principales especies y categorías de hongos aislados en rizósfera y rizoplano en suelos tratados.}

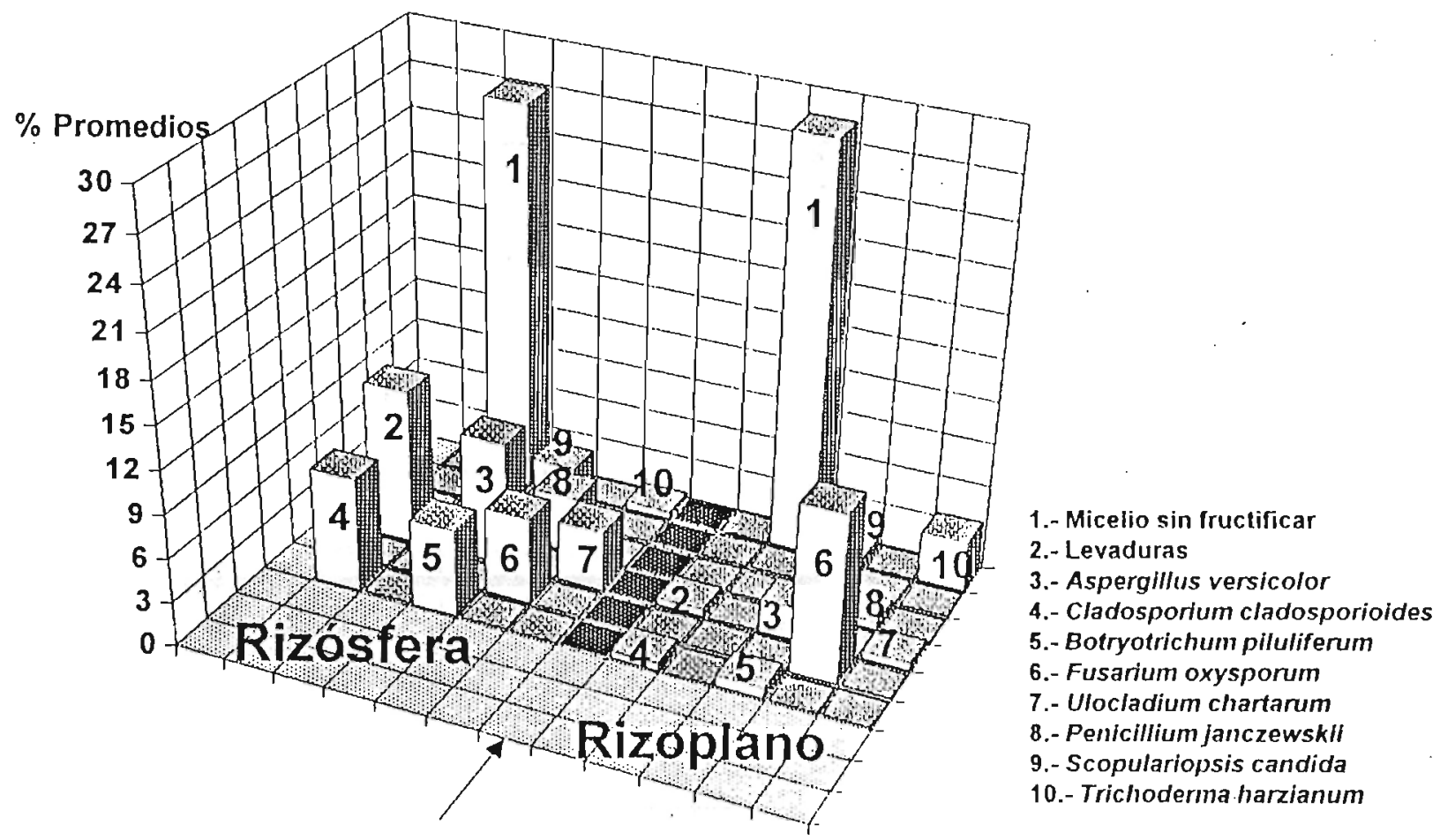

(Campbell,1985). A pesar que las baclerias y los Actinomycetes son numéricamente superiores a los hongos en estos dos habital, estos últimos presentan una mayor biomasa y por ende en las raices, ocupan más superlicic cue las baclerias, constituyendose en los principales colonizadores de las células vegetales mucrtas, en especial aquellos capaces de producir diversos tipos de celulasas ( Burges \& Raw, 1971; Cooke, 1979: Ly'nch, 1979).

En nuestros resullados, acordes a las limilaciones de la metodología empleada, la proporción de hongos considerados saprólitos, es mayor que la de los polcnciales patógenos en ambos habitat; esta siluación es importantc, debido a que, la compelencia por el sustrato y cl anlagonismo, pueden derivar en un menor número de actividales en estosúltimos (Toussoun el al., 1970; Bakcr \& Cook, 1974; Weste \& Vithanage 1977; Schippers \& Gams, 1979; ^shton \& Willis, 1982; ()camb \& Kommedalıl, 1994a).

I.a literatura nacional es escasa en inlomacioul relacionada a la micota de la rizóslera y del rizoplano de Eucalyptus spp, solo existen considenciones gencrales sobre cl parasitismo fúngico en cstos árboles, en los trabajos de lpinza (1990,1991,1992) y Prado \& Barros (1991).

La presencia en estos dos ambientes de dilerentes microorganismos, ya sea benćlicos o delctereos; los primeros con capacidades para inlluenciar favorablemente el crecimiento del vegetal y las cosechas mediante el aporte de nutrientes, mincrales, substancias cstimulantes del crecimicnto y la capacidad de suprimir los microorgansimos dañinos. Jos segundos, mediante iones, alteraciones del aporte hidrico o alicelando en loma negativa la función de las substancias de crecimienlo raclicular (Schipper el al, 1987).

Ein nuestro trabajo, la variación estacional en la compresicion y frecuencia de especies varió ampliamente hacia el final del cstudio cn ambos substratos, especialmente cn el rizoplano y el máximo numero de colonias registradas en el muestreo de invieno, puede guardar cierta relación con el incremento de cxudados y tejidos senescentes ( $Y$ ip) \& Westc, 1985).

Jin un análisis de los integrantes de los taxa callificados como palógenos o palógenos pelenciales (segudn Rossman ct al., 1987) cn ambossubstratos, ćstos fuerom represcontados principalmente por cejecics de Alternaria, Aspergillus, Fusarium (encspecial F.oxysporum), Phoma herbarumy: Pythium ulhmum, los cuales lueson aislados junlo a un conjunto de poblaciones saprófitas, integradas principalmente por los géneros Acremonium, Penicilliwn y. Ulocladium, demostrandese apalentencule en anbos grupos, buenas capacidades competitivas, particularmente en el rizoplano, donde las interaceiones y antagonismos se presentan en gradus más clevados, pudicndo cjercer ambos grupos de especies, un rol importante en el control de los Titopatogenos alocloms (Manimulhat et al, 1987). Como la frecuencia y dommancia de los honges del rizoplano parcece dilerir ampliamente en relación al lipo de planta estudiada. las condiciones edilicals o el clima, resula evidente que 
este habitat es más selectivo que la rizósfera, por la cantidad de nutrientes aportados (Yip \& Weste, 1985).

En nuestra investigación, un grupo especifico de taxa mantuvieron buenos porcentaje de presencia durante casi todo el período de muestreo en ambos habitat. Entre ellos, se detectó la presencia de algunos patógenos potenciales o saprófitos de interés distribuidos en los géneros Aspergillus, Botryotrichum, Cladosporium, Fusarium, Penicillium, Pythium y Ulocladium.

La dominancia del género Aspergillus, en ambos substratos, puede deberse a su resistencia a las fumigaciones y otros tratamientos del suelo para el empleo agricola o forestal. Su capacidad de producir pigmentos, substancias bactericidas, antifúngicas e insecticidas y su bajo poder patogénico, permite incluirlo dentro de los integrantes de gran utilidad en la rizósfera. A.flavus, es de importancia por la producción de micotosinas en granos y otros ambientes, mientras otras especies se asocian a enfermedades de algunas semillas. A.fumigatus es muy común en suelos forestales y viveros (Domsch et al., 1980), sin embargo su presencia en rizósfera fue escasa y no existen aparentemente registros en Chile de su aislamiento en estos habitat específicos. A. versicolor es dominante en rizósfera en los 3 muestreos ya sea en suelos tratados como control, sin embargo su disminución en el tiempo en el rizoplano de los suelos tratados, no es comparable con lo que sucede en el suelo control, cuyas frecuencias a pesar de ser menores que en la rizósfera, se mantienen constantes en las 3 etapas demuestreo de las plántulas. Esta situación puede atribuirse, más que a la aplicación de fungicidas (que no afectaron aparentemente sus aislamientos en la rizóstera), a posibles fenómenos de competencia o antagonismo con especies de Trichoderma, Fusarium, Penicillium y Ulocladium, que mantuvieron frecuencias mayores en el rizoplano que en la rizósfera (a excepción de Trichoderma).

A.versicolor ha sido poco reportado en suelos forestales, pero se ha observado una rápida recolonización por esta especie en suelos de citricos, previamente fumigados (Domsch el al., 1980). En Chile, la literatura no intorma de la presencia de especie de Aspergillus en ambientes similares (Mujica \& Vergara, 1980).

Botryotrichumpiluliferum Sacc. \& March., anamorlo de Chaetomium piluliferum, es un hongo de amplia distribución en diferentes suelos. A pesar que las técnicas corrientes de dilución no permiten facilmente su aislamiento, debido a su abundancia, fue posible aislarlo en la rizóslera y rizoplano de los suelos control con la más alta presencia de todas las cepas aisladas. Su constante prescncia en el primer habitat en suelos tratados, indica su posible relativa resistencia a los agroquimicos, pero la disminución de su prevalencia en rizoplano, indica un posible desplazamiento por especies más competitivas.

Cladosporium, es un género cosmopolita que posee especies saprófitas y patógenas débiles, se le considera el más común en el aire en muchos paises y un colonizador del suelo, de material vegetal en descomposición. En la rizósfera es uno de los principales componentes de la micota del filoplano de gramíneas y árboles (Ellis, 1971, 1976; Domsch et al.,1980; Campbell,1985; Ellis \& Ellis,1985). C. cladosporioides fue la especie más común en rizósfera, pero practicamente desaparece en el rizoplano de las plántulas tratadas, siendo su rol netamente saprotrofo, su presencia es úti] por tratarse de un competidor de rápido crecimiento.

EnChile, C. herbarum es el más citadoen la literatura (Mujica \& Vergara, 1980), pero en nuestra investigación su presencia fue escasa.

Las especies del género Fusarium, son comunes en todo tipo de suelo, pero son bien conocidas como patógenas en viveros forestales en muchas partes del mundo (Butin \& Peredo, 1986; Viljoen et al.,1992; Viljoen \& Wingfield, 1994). Las enfermedades asociadas a este grupo de hongos incluyen, marchitamiento de semillas, dampingoff, pudrición de raices y cancros del tallo ( Bloomberg, 1976; Ipinza, 1991, 1992). Son particularmente dañinas en los viveros de pinos, especialmente $F$. oxysporum, que se ha identificado como el mayor patógeno de raices desnudas y en los contenedores de plántulas en crecimiento. Esta situación no es desconocida en Chile, siendo coincidente con aislamientos realizados en viveros de Pinus radiata D. Don, (Herrela, 1962; Tay, 1969; Kunstmann, 1978; CONAF, 1981), en Euculyptus spp. (Muñoz, 1986; Prado \& Bartos, 1991, Ipinza, 1992), asi como en viveros de almendros y damascos (Pinto, 1968).

Butin \& Peredo (1986), consideran a las especies de Fusurium como las mayores causantes de problemas en viveros forestales, ya sea parasitando semillas o después de la emergencia de la planta, debido a la producción de toxinas y enzimas celuloliticas. Como geohongo, $F$. oxysporum, representa un modelo interesante para el estudio de las poblaciones autóctonas del suelo. Su alta resistencia a los lungicidas y la presencia de cepas patogénicas con habilidad de causar marchitamiento vascular en algunos hospedadores (Pinus radiata), pero principalmente por su rol de colonizador asintomático o saprófito; puede ejurcer una presión selectiva más severa sobre las cepas patogénicas, permitiendo a los saprófitos adaptarse ampliamente a la colonización de las raices y materia orgánica presente en la rizósfera (Gordon \& Okannoto, 1992). La variabilidad en el tiempo de esta especie u otras, consideradas como "competentes de la rizósfera", puede olirecer ventajas en la invasión de los tejidos radiculares del hospedador bajo condiciones de estres (oportunismo), o en su capacidad saprolitica competitiva por el substrato. Esta última, puede inlluenciar, limitar o suprimir (por antagonismo) el establecimiento de otros patógenos potenciales, incluso de su misma especie (Ocamb \& Kommedahl, 1994b), ya sea por su posición en la población o la concentración de propágulos en el habitat. 
Las especies no patogénicas de $F$. oxysporum han sidode particular interes en muchosestudios de colonización fúngica de raices, por su relativa abundancia sobre muchas especies vegetales que crecen en distintos tipos de suelo. Aún en baja densidad, es capaz de colonizar y competir mejor que otros geohongos con densidades mucho mayores(Parkinson \& Pearson, 1967; Appel \& Gordon, 1994). Su aumento de presencia en el rizoplano de nuestras plántulas, puede relacionarse con todos estos factores mencionados y especialmente atribuirle un rol antagónico junto con Trichoderma harzianum y a los integrantes del pool de hongos calificados como micelios sin fructificar.

Otros competentes de la rizósfera como $F$. moniliforme y $F$. solani, son considerados patógenos en amplios rangos de hospederos, sin embargo ambas especies solo se presentaron en algunas estapas del crecimiento de las plántulas y al parecer fueron desplazadas en su capacidad competitiva, por $\boldsymbol{F}$.oxysporum. Vaartaja (1967), en un estudio en vivero, realizado en Australia, encontró una alta incidencia de aislamientos de $F$. oxysporum y $F$. solani, en plantas aparentemente sanas, donde ambas especies se comportaron con baja virulencia. La presencia de otros Fusarium en las 3 etapas del muestreo no parece interferir aparentemente en la dominancia de $F$. oxysporum, en ambos substralos. Kunstmann (1978), en una revisión de la micota de 8 viveros forestales de la X Región (con suelos tratados), pudo concluir que a pesar de la aplicación de fungicidas, éstos no inhibieron la participación de $F$. oxysporum en la colonización de los suelos. Swettingam (1989), trabajando en almacigos de lupino, sugiere que los fungicidas Rovral, Benolate y Ridomil, usados en combinación, pueden aumentar la severidad de hongos invasores secundarios tales como Fusarium spp., Pythium spp. y posiblemente otros hongos.

El género Penicillium, fue el más diversoen especies, su presencia mayor en las plántulas en post emergencia en los 2 habitat y en especial en suelos tratados, sugiere una capacidad de colonización más tardia de la rizósfera y el rizoplano. P. janthinellum, la única especie presente en los tres muestreos, es muy común en el suelo en lodos los habitat y latitudes, soporta con cierta dilicultad las fumigaciones y su antagonismo con bacterias y diversos hongos patógenos lo convierte en un microorganismo de utilidad en los suelos(Domsch el al., 1980). Se ha aislado en la rizósfera de Eucalyptus regnans y en Cyperaceae y Proteaceae en Australia con buena firecuencia (Ashton \& Willis, 1982; Yip \& Weste, 1 985), perono existe información en la literatura nacional.

$P$. junczenvskii, es la segunda especie de interés en rizósfera de bosques adultos de $E$. regnans. Christensen et al.(1962), en un estudio de poblaciones de microlıngos en suelos de 5 predios de Arce-Olmo, usando el método de dilución, encontraron también una dominancia de especies de Penicillium y Ulocladium.
En los viveros, la podredumbre de los semilleros y el marchitamiento descendente, son enfermedades complejas y muy distribuidas, que pueden producir notables pérdidas en los almácigos antes y después de la emergencia. Los agentes involucrados en los eucaliptos, pueden ser entre otros Pythium spp.("damping-off") y Phytophthora spp. ("die-back") (.Jacobs, 1981). Pythium spp, se menciona en la literatura de viveros forestales en Chile, principalmente en coniferas (Tay, 1969; Mujica \& Vergara, 1980; CONAF, 1981). En viveros de Eucalyptus se ha reportado causando "damping-off" en Brasil, Cuba y Chile(Métro, 1976; Jacobs, 1981; Muñoz,1986; Prado\& Barros, 1991; Ipinza, 1992). Kunstmann (1978), basandose en la literatura, consideró a Pythium ultimum, causante de caida de pre y postemergencia en viveros de coniferas. En nuestros cultivos $P$. ultimum var. ultimum, se aisló en los tres muestreos en el rizoplano con un $100 \%$ de presencia en el medio selectivo, esto indica que los fungicidas utilizados solo restringen parcialmente su crecimiento y distribución, pero no logran eliminarlo. A] respecto, Tay (1969), usando la técnica de lavado de suelo, aisló Pythium sp. en un vivero forestal de Chillán, a pesar que los suelos eran tratados con fungicidas (Dexon, Captan y otros). Este autor luego de varios ensayos concluye que: Dexon, Captan y otros fungicidas, no ejercen un control eficaz sobre Pythium sp., esto se confirma con el trabajo de Tollenaar et al.(1970), quienes también aislaron Pythium sp. en el mismo vivero y con igual tratamiento fungicida. Los exudados de las raices de diferentes almácigos, estimulan el crecimiento de las hifas de $P$. ultimum var ultimum, siendo capaces de resistir en los suelos por tiempos superiores a I año (Plaats-Niterink, 1981). Las especies de Pythium se consideran con poca capacidad competitiva en los suelos, si se les compara con otros organismos capaces de colonizar las raices y a menudo actuan solo como colonizadores secundarios; su acción patógena se observa prelerentemente en vegetales bajo condición de estrés. P. ultimum parece ser incapaz de atacar semillas inoculadas con $T$. viride, en suelo libre de hongos patigenos, (Wicklow \& Carrol, 1981). Sin embargo la presencia de T. harzianum en el rizoplano de nuestras plántulas, no tue un impedimento en el aislamiento de esta especie. Diversas poblaciones de Pythium spp. se han detectado en los suelos de plantaciones de Euculyptus, considerandose en décadas pasadas, como simples habitantes del suelo y no patogénicas para el establecimiento de estas plantas. Sin embargo, algunos autores establecen que estas especies pueden ser concomitantes en un conjunto de enfermedades con Phytophthoraspp. enespecial P. cinnamomi. (Smith et al., 1989; Linde et al., 1994). P.ultimum, se ha registrado causando también patologías en frutales chilenos, tales como: damascos, almendros, carozo (1'into \& Mirsetich, 1976).

La presencia de $P$. ultimum en el rizoplano, no es exclusiva de este habitat y es perfectamente posible extrapolar 
su presencia a la rizósfera si se hubieran empleado también las técnicas de dilución en medios selectivos, sin embargo nos bastó con detectar su presencia en las raices de suelos tratados. En los suelos no tratados su presencia podría ser una de las causas más importantes de caída de las plántulas de control.

Ulocladium, es otro género cosmopolita, generalmente saprófito, común en el suelo, semillas; ramas y hojas de diferentes plantas. U.atrum, es una de las especies más comunes que colonizan tejidos necróticos en varios ambientes, en especial la filósfera, adaptandose rápidamente a los cambios de las condiciones microclimáticas en el campo (Köhl et al., 1995). Los reportes de su poder patógeno en plantas son raros en la literatura, sin embargo su alta capacidad saprofitica competitiva con Cladosporium spp.y B. cinerea, lo hacen un atractivo candidato para el biocontrol, en especial por su capacidad de suprimir la esporulación de B.cinerea en los tejidos necróticos. (Linke et al., 1 992; Köhl et al.,1995). Esta especie se ha detectado en vides y perales (Mujica \& Vergara, 1980), mientras.Kunstmann (1978), lo aisla como integrante saprofítico en el suelo y en plántulas de viveros de pinos de la $\mathrm{X}$ región.

La presencia esporádica en raiz de algunos patógenos que generalmente no estan presentes en rizósfera,como especies de Alternaria, Cylindrocarpon, Drechslera, Myrothecium, Paecilomyces, Verticillium, parece no alterar la posible competencia ejercida por la dominancia de $F$. oxysporum, Trichoderma y los hongos con micelios sin fiuctificaciones.

En rizoplano, en las tres etapas de muestreo, se aprecia un aumento de hongos patógenos en el tiempo y según. Wicklow \& Carrol (1981), la superficie de la raíz cubierta por hongos aumenta a medida que aumenta la edad de las plantas, esto puede ser una explicación para el aumento de la población fungica detectado en cada muestreo, principalmente en la etapa de postemergencia.

El aislamiento esporádico de Botrytis cinerea en rizósfera, en las plántulas de 6 a 7 meses merece un breve comentario; a pesar de ser considerado un taxa patogénico para muchos hospedadores, entre los que se encuentran las especies de Eucalyptus en viveros; tanto en Chile como en otros paises (Herrera, 1968; De la Lama 1976; Métro, 1976; Domsch et.al., 1980; CONAF, 1981; Muñoz, 1986; Butin \& Peredo, 1986; Prado \& Barros, 1991; Ipinza, 1992); llama la atención su baja presencia en el suelo, situación contraria a lo que sucede en otras regiones de Chile, especialmente la X Región (Butin \& Peredo, 1986; Kunstmann, 1978). Por sus estructuras de resistencia (esclerocios), B.cinerea es más bien considerado un colonizador de los horizontes superiores del suelo y no de las raices (Domisch et al., 1980). Su escasa participación solo en rizósfera, podria relacionarse al efecto biocontrolador de $U$. atrum, Gliocladium spp.y $T$. harzianum (Köhlet al, 1995), pero debe sumarse la aplicación en el vivero de fungicidas específicos (Euparen).

La presencia de Trichoderma, en las tres etapas de muestreo, con una alta participación en la etapa de preemergencia y menor en el período de emergencia, puede ser una explicación de la controlada participación de otras especies patógenas.Varias especies del género son consideradas como inhibidoras del crecimiento de patógenos, tales como: Rhizoctonia, Pythium y Phytophthora y en la prevención de colonización de tocones por Fomes annosus (Wicklow \&Carrol, 1981.).

A pesar que nuestros objetivos principales se orientaron a los hongos aislados en ambos substratos en suelos tratados, mientras los cultivos en suelos control se analizaron solo con un fin comparativo, merece mencionarse que: como en la rizósfera (control), el porcentaje de participación de patógenos fue mayor que en suelos tratados, en ambos substratos y en las tres etapas estudiadas. Esto justifica en cierta medida el uso de agroquímicos en la disminución de las comunidades patogénicas. Los porcentajes relativamente estables de hongos patógenos en el rizoplano (control), durante los tres muestreos, se debe probablemente a un control biológicoentre las poblaciones, entre otros factores edáficos o climáticos. En un ensayo realizado por Tay (1969), se obtuvo en suelo testigo (control), mayor número de plantas sanas que en suelos tratados con fungicidas, situación que se atribuyó a que la acción de éstos fue mayor sobre la micota antagónica de los patógenos, causando una reducción de organismos competidores, produciendose de esta forma una interferencia en el control biológico, lo que no sucede en el testigo. En rizósfera (control), la participación de patógenos potenciales es menor cualitativamente que en el rizoplano; Fusarium spp ( principalmente F.oxysporum), comparte con Aspergillus spp.( principalmente $A$. versicolor) su alta presencia, pero este último es desplazado a un segundo lugar en el rizoplano, posiblemente por la aparición de competidores más adaptados al habitat (Alternaria spp. y Trichoderma spp.).

Nuestro estudio solo involucra a los hongos obtenidos en condiciones de campo, aislados e incubados a temperatura ambiente $\left(13-23^{\circ} \mathrm{C}\right)$, por ende la metodología solo seleccionó primariamente las especies con alta densidad de inoculum y las que exibieron rangos optimos de crecimiento entre estas temperaturas, según los períodos estacionales (Carreiro \& Koske, 1992). Esta situación necesariamente no indica la actividad de los propágulos de dispersión presentes en el tiempo de recolección y seguramente, otras especies con menor velocidad de crecimiento o requerimientos más bajos de temperatura, fueron desestimadas. Consecuentemente, la composición y estructura de nuestras comunidades puede reflejar ciertas diferencias que deberán considerarse en futuros estudios $\mathrm{y}$ análisis similares.

$\mathrm{Si}$ bien es cierto que una estable y resilente 
comunidad, contiene un nivel valorable y útil de diversidad taxonómica, la importancia de sus integrantes guarda más relación con la función que desempeñan en ésta. Los estudios de grupos taxonómicos basados primariamente en su función debiera ser el próximo paso para delucidar la dinámica y la salud del ecosistema analizado (Miller, 1995).

Debe destacarse que muchos de los integrantes de la Tabla 1, no se han descrito con anterioridad en Chile en estos habitat.

\section{CONCLUSIONES}

En el rizoplano de los suelos tratados, existe una mayor cantidad de patógenos potenciales que en rizósfera, situación que se mantiene en suelos control a pesar que en éstos últimos las diferencias entre ambos habitat son menores. La presencia de patógenos potenciales en el rizoplano aumenta en relación a la edad de las plántulas, situación que se observa de manera aparentemente inversa en rizósfera.

La variedad de patógenos potenciales es mayor en rizoplano que en rizósfera, sin embargo la presencia de F.oxysporum, en ambos sustratos, demuestra su posible capacidad antagónica, su habilidad de competente de la rizósfera y de colonizador epifito o endófito del rizoplano.

La mayor presencia de hongos saprólitos en suelos tratados, mantienen un grado necesario de competencia y posible antagonismo en ambos sustratos, colaborando en el control de fitopatógenos (P.ultimum, A.ulternata, Ph.leveillei), junto a las especies competentes de la rizósfera (T. harzianum y $F$. oxysporum).

La abundante presencia de patógenos de caida, en las raices de plántulas, como $P$. ultimum y $F$ oxysporum, puede ser una de las causas de infección sistémica presentes o futuras.
Observando el comportamiento global promedio de las 10 principales especies o categorías de hongos en ambos sustratos, puede apreciarse que la mayoria de ellas disminuye en frecuencia y dominancia en el rizoplano, con excepción de F.oxysporum, T. harzianum y los micelios sin fructificar, que presentan aumentos de sus aislamientos.

El hecho de que la región radicular sea un microhabitat donde la abundancia-actividad de los microorganismos es intensa y donde las relaciones de asociación y antagonismo presentan un grado más elevado que en el resto de los microhabitat del suelo, la convierten en la primera línea de defensa de las plantas frente al ataque de organismos patógenos. Es por esto que debe considerarse el empleo de agrotóxicos, los cuales ejercen una selección y cambios poco predescibles en la dinámica poblacional, la cual puede restringir el contro biológico natural. Estos productos, logran inhibir el crecimiento de ciertos patógenos y saprófitos, en favor de olros, pero al parecer no pueden erradicarlos totalmente del suelo y raices de las plantas.

La presencia en raices de P.ultimum, A.alternata, F.oxysporum y $P h$. leveillei, puede indicar colonización y posibilidad de infección sistemica, sin embargo el buen estado general fitosanitario, sugiere que la presencia o penetración en el hospedador a pesar de ser necesaria para la infección, no siempre es una condición suficiente para el inicio de la enfermedad.

Debido al manejo intensivo de los suelos de viveros, los cambios o persistencia de diferentes poblaciones fúngicas, y las interacciones de 2 de sus principales integrantes, tales como P.ultimum y $F$. oxysporum, u olros posibles patógenos de raices resistentes a las fumigaciones, deben evaluarse fitosanitariamente mediante controles periódicos en beneficio de su productividad.

\section{REFERENCIAS}

Appel,D.J. \& Gordon,T.R. (I994). Local and regional variation in populations of Fusarium oxysporum from agricultural ficld soils. Phytopathology. 84:781-789

Ashton,D.H. \& Willis, E.J.(1982). The Plant Comunity as a Working Mechanism;Antagonisnis in the regeneration of the Encatyptus regnams in the mature forest. E.J. Newman(ed.). Australia.

Baker,K.F. \& Cook,R.J.(1974).Biological control of plant pathogens. San Fransisco.W.H. Freeman \& Co.

Bloomberg, W.J. (1976). Distribution and pathogenicity of Fusarum oxpsporum in a forest nursery soil. Phytopathology 66: 10901092.(Original no consultado, citado por Viljoen, A. \& Winglicld, M.J. 1994. Firt report of Frsarinm subghtinans f. sp. pini on pini seedlings in South Africa. Plant Dis. 78:309-312
Borquez,L.(1987). Efecto de Fpoca de Repique, Duración de sombreado y Tamaño de Maceta en la Producción de Plantas de Euculiptus globulus Labill en la Zona Central de Clile. Tesis lng. For. Valdivia, Universidad Austral de Chile. Facullad de Ciencias Forestales.

Burges,A. \& Raw,F.(1971).Biología del Suelo. Barcelona. España.Ediciones Omega, S.A.

Burschcl,P. \& Martinez,O.(1968). Ensayo sobre la influencia de densidad y fertilización en la producción de plantas de Pinus radiata D.Don. Valdivia, Universidad Austral de Chile,Facultad de Ciencias Forestales, Publicación Cientifica $N^{\circ} 11$

Butin,1L. \& Peredo,H.L.(1986).Hongos parásitos en coniferas de América del Sur, con especial relérencia a Chile; Bibliotheca Mycologica. J. Cramer(ed.). Berlin. Alemania 
Camplbell, R. (1985). Plant Microbiology. Edwards Arnold(ed.). London.

Carreiro,M. \& Koske,R. (1992). Room temperature isolations can bais against selection of low temperature microfungi in temperate forest soils. Mycologia. 84:886-900.

Cochran,W.(1973). Diseños Experimentales. México D.F. Editorial F. Trillas S.A

Cooke,W.B.(1979). The Ecology of Fungi. Florida,EEUU. CRC Press Inc.

CONAF. (1981). Manual de Prospección Fitosanitaria; Programa de Control de Plagas y Enfermedades Forestales. 2a ed.. Stgo..Chile. Ministerio de Agricultura. Corporación Nacional Forestal.

INFOR-CORFO.(1991). Disponibilidad futura de madera de Eucalipto.Santiago, Instituto Forestal. 46p.(Boletin de Mercado Forestal,Año $X, N^{\circ} 125$.)

INFOR (Chile). (1993). Estadisticas Forestales 1992. Santiago, Inslituto Forestal.(Boletin Estadistico No30.)

Christensen,M.: Wittingham,W.F. \& Novak,R.O.(1962). The soil microfungi of wet mesic forests in southern Wisconsin. Mycologia. 54: 374 .

Daniel,P.;Helms,V. \& Baker,F.(1982). Principios de Silvicultura. México,México. Libros Mc Graw-Hill de México S.A.

Domsch,K.H;Gams,W. \& Traute-Ileidi Anderson. (1980).Compendium of Soil Fungi. Volume 1.London, England. Academic Press Lid.

Ellis, M.B.(1971). Dematiaceus Hyphomycetes. Commonwealth Agricultural Bureaux, Commonwealth Mycological Institute. Kew, Surrey, England.

.(1976).More Dematiaceous Hyphonycetes. Commonwealth Agricultural Bureaux, Commonvealth Mycological Institule. Kew, Surrey, England. 507p.

\& J.P.Ellis.(1985).Microfungi on Land Plants; An Identification Hand Book. London, England. Croom Helm Lid.

Gams, W.; Aa,II.A. Van Der ; Plaats-Niterink,A.J. Van Der; Samson, R.A. \& Stalpers, J.A. (1987). CBS Course of Mycology, Third Edition. Baarn.CBS.

Gordon,T.R. \& Okamoto,D. (1992). Population Structure and the Relationship Between Pathogenic and non Pallwogenic Strains of Fusarium oxysporum. Phytopathology. 82:73-77

Ilerrera,S.(1962). Siete enfermedades y plagas de los viveros lorestales y del pino insigne. Minislerio de Agricultura, Departamento Forestal, Sección de Experimenlación Forestal.5-12.(Original no consultado, citado por Tay,J.L. 1969. Un Estudio de los Organismos Causales de la Caida en Pinus radiata D. Don en el Vivero Forestal de Chillán. Tesis Escuela de Agronomia. Universidad de Concepción, Chillán.

(1968). Siete enfemedades y plagas de los viveros forestales $y$ del pino insigne. Bol. Depto. For. Min. Agr. Chile. (Original no consultado, citado por Mujica,F. \& Vergara,C.1980. Flora Fungosa Chilena.2a ed. Santiago, Universidad de Chile, Facultad de Agronomia,

\section{Cs. Agrícolas $\mathrm{N}^{\circ}$ )}

Ibarra,V. \& Valenzuela,J.(1980).Ensayo de nuevas técnicas para producción de plantas de Rauli, Nothofagus alpina(Poepp, et Endl.) Oerts. Tesis Ing. For. Santiago, Universidad de Chile, Facultad de Ciencias Agrarias y Forestales

Ipinza,R.(1990). Algunas consideraciones y rellexiones sobre la fragilidad de nuestros bosques a plagas y enfermedades forestales. Santiago, Chile Forestal, Documento Técnico $\mathrm{N}^{\circ} 48$.

(1991). Hongos parásitos de los Eucabyptus, En: Actas I Jomadas de Sanidad Forestal, Antecedentes Fitosanitarios en Eucabyptus y Bosque Nalivo. CONAF, CORMA y Universidad Austral de Chile. Valdivia, Clile. 30 y 31 de Octubre de 1991

(1992). Algunas consideraciones sobre la protección fitosanitaria en el cultivo de los encaliptos. Santigo, Chile Forestal, Documento Técnico $\mathrm{N}^{\circ} 61$.

Jacols, M.R.(1981). El Eucalipto en la repoblación forestal. Roma, Italia. FAO.

Kannwischer, M. E. \& Mitchell, D.J. (1978). The influence of a fingicide on the epidemiology of black shank of tobacco. Phytopathology. 68: 1760-1765.

K'lich,M. \& Pitt,J.(1988). A laboratory guide to common AspergilIns species and their teleomorphs. Australia. Commonwealth Scientilic and Industrial. Research Organization. Division of Food Processing

Köhl,J.; Molhoek,W.M.L.;Plas,C.H.Van Der \& Fokkema,N.J.(1995). Efect for Ulocludium atrum and other antagonists on sporulation of Borngris cinerea on Dead Lily leaves exposed to field conditions. J, Plant Pathol, 85: 393-401

Kunstmann, E.(1978). Prospección Micológica en Viveros de la X Región. Tesis Ing. For. Valdivia, Universidad Austral de Chile, Facultad de Ciencias Forestales

Lama, G. De La. (1976). Atlas del Eucalipto. Tomo I. Infonmación y Ecologia. Sevilla, España.Ministerio de Agricultura, INIA, Inst. Nac. para la Conservación de la Naturaluza(ICONA)

Linde,C.; Wingfield,M.J. \& Kemp,G.II.J.(1994). Root and root collar diseases of Encabprus grandis caused by Pythium splendens. Plant Dis. 78: 1006-1009.

Linke,K.II.; Scheibel,C.; Saxcna,M.C. \& Sauerborn,J.(1992), Fungi occurring on Orobanche spp. and their preliminary evaluation for Orobanche control. Trop. Pest Manage. 38: 127-130

Lymch,J.M. (1979) .7he terrestrial environment. In : Linch.J.N \& Poole,N.J.(eds.)Microbial ecology: A conceptual approach. Blakwell, Oxford. 69-71

Mackay, A. \& Weste, G. (1985). Survival of Phyrophthora cinnamomi in Encabptus roots buried in forest soils. In : Parker, C.A. et al. (eds). Fecology and management of soillorne plant pathogens. St. Paul, Mimesota, U.S.A. The American Phytopatl. Soc. 45-47

Manandhar,J.B; Thapliyal,P.N; Cavanaugh,K.J. \& Sinclair,J. B. (1987). Interalion Between Pallogenic and Saprobic Fungi lisolaled from Soybean Rools and Seeds. Mycopallology. 98 : $69-75$ 
Métro,A.(1976). Eucalypts for Planting. Roma, Ilaly. FAO. 398p.

Miller,L.S. (1995). Functional diversity in fungi. Can.J.Bot. 73 (Suppl.1): S 50-57)

Mujica,F. \& Vergara,C. (1980). Flora Fungosa Chilena.2a ed. Santiago, Universidad de Chile, Facultad de Agronomía, Cs. Agricolas $\mathrm{N}^{\circ} 5-308 \mathrm{p}$

Muñoz, A. \& Perez,A.( 1981). Factores que influyen en la producción de plantas de Acacia caven (Mol) Hook et An y Prosopis chileinsis (Mol) Stuntz. Tesis Ing. For. Santiago, Universidad de Chile, Facultad de Ciencias Forestales.

Muñoz, A. (1986). Manual para la producción de plantas de Eucalipto en Macetas. Documento de trabajo $n^{\circ} 2$, Investigación y desarrollo de áreas silvestres, zonas áridas y semiáridas de Chile. CONAF/PNUD/FAO-CHI/83/017 Santiago de Chile.

Nelson, P.E.; Toussoun, T.A. \& Marasas,W.F.O. (1983). Fusarium species: An illustrated manual for identification. The Pemusylvania State University Press. University Park, Pennsylvania U.S.A.

Ocamb,C.M. \& Kommedahl,T. 1994a. Growth of rhizosphere competent and incompetent Fusarium species from corn carbon susbtrates. Phytopathology. 84: 508-514

$$
\text { . \& }
$$
1994b. Rhizosphere competence of

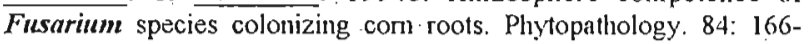
172

Parkinson, D. \& Pearson,R.(1967). Studies on fungi in the root region. VII. Competitive ability of sterile dark fungi. Plant Soil. 27 : 120.130

Pinto de Torres,A. (1968). Especies patógenas en viveros y plantaciones nuevas de frutales en Chile. Agr. Téc. 28:142-130. (Original no consultado, citado por Mujica,F. \& Vergara,C.1980. Flora Fungosa Chilena:2a ed. Santiago, Universiuad de Chile, Fac. de Agron., Cs. Agrícolas $\mathrm{N}^{\circ} 5$ )

\& Mircetich,S.M.(1976). P.thium ultimum Trow causante de "pudrición del tronco" en plántulas de frutales de carozo $y$ en almendros y damascos de dos años. Agr. Téc. 36: 17/-173.

Pitt,J.(1979). The genus Penicillinm and its Teleomorphic States Eupenicillinm and Talaromyces. London, England. Academic. Press Inc.

Plaats-Niterink, A.J. van der. (1981). Monograph of the genus Pythium. CBS. Baarn $\mathrm{N}^{\circ} 21$.

Prado,J. \& Barros,S.(1991). Eucatyptus: Principios de Silviculura y Manejo. Tercera Edición. Santiago, Inslituto Forestal. División de Silvicultura.
Rossman, A.Y;; Palm,M.E. \& Spielman, L.J. (1987). A literature guide for the identification of plant pathogenic fungi. APS Press St. Paul, Minnesota.

Schippers,B. \& Gams, W.(1979). Soil-borne plant pathogens. London. Academic Press.

.; Bakker,A. \& Bakker,P.(1987). Interactions of deleterious and benefical rlizosphere microorganisms and the effect of cropping praclices. Ann. Rev. Phytopathol. 25:339-358

Smith,I.W.; Marks,G.C.; Featherston,G.R. \& Geary,P.W. (1989). Effects of inter-planted wattles on the establislument of eucalypls planted on forest sites affected by Phytophithora cinnamomi Aust. For. 52:74-8!

Swectingham, M.W. (1989). Fungi associated will rool and Hy'pocolyl Diseases of seedling Lupins in Westem Australia. Aust. J.Agric. Res. 40:781-789

Tay,J.L.(1969). Un esludio de los organismos causales de la caida en Pinus radiuta D. Don en el Vivero Forestal de Chillán. Tesis Escuela de Agrononía. Universidad de Concepción.

Tollenaar,II.; Bleiholder,H. \& Vera, A. (1970). Observaciones de nuevas enfermedades Agr.. Técnica 30:5 l-54

Toussoun,T.A.;Bega,R.V. \& Nelson,P.E. (1970). Root diseases and soil-borne pathogens. Berkeley, Univ. Califonia Press.

Vaartaja,O. (1967). Dumping-off pathogens in South Auslralian nurseries. Phylopathology. 57:765-768

Viljoen,A. \& Wingficld,M.J. (1994). First report of Fusarium subglutinans t. sp. pini on pini seedlings in Sontl Africa. Plant Dis. 7.8:309-312

; . \& Crous,P.W. (1992). Fungal pathogens in Pinus and Eucohtptus seedling nurseries in South Africa: A revievv. S. Afr. For. J. I.61: 45-51.(Original no consultado, citado por Viljoen,A. \& Wingfield,M.J.1994.Firt report of Fusarium subglutinans $\mathrm{f}$. sp. pini on pini seedlings in South Africa. Plant Dis. 78:309-312

Weste,G. \& Vithanage,K. (1977). Microbial population of lorest soils. Aust. J.Bot. 25:153-167

Wicklow,D. \& Carrol,G.(1981). The Fungal Community. New York, EELrU. Marcel Dekker, Inc.

Yip,II.Y. \& Weste,G.(1985). Rhizoplane Mycoflora of Gahnia rodula and Isopogon ceratophyllus in soils infested and free from Phytophthora cinnamomi. Aust. J. Bot. 33:92-98 